\title{
Trends of suicides in Galle-Sri Lanka
}

Rathnaweera RHAI ${ }^{1}$

Department of Forensic Medicine, Faculty of Medicine, Karapitiya, Galle, Sri Lanka

*Corresponding author: Tel: 0094-772969060. E-mail address:ajithrathnaweera@yahoo.com

MLJSL.Vol 2. No 1. Mar. pp 5-10

\begin{abstract}
Introduction

Suicide is considered as a complex event that has biological, psychological and social implications. For many years now Sri Lanka has been among the countries where suicide and attempted suicide have been frequent.
\end{abstract}

\section{Objective}

To document epidemiological and socio-economic data on suicides reported to the Teaching hospital, Karapitiya in the year 2011 and to compare with the findings of previous studies done in other parts of the country.

\section{Materials and Methods}

All suicidal deaths reported to Teaching hospital, Karapitiya from $1^{\text {st }}$ of January 2011 to $31^{\text {st }}$ of December 2011 were studied retrospectively.

\section{Results}

During the study period, 110 deaths due to suicide were documented and analyzed - 86 males (78\%) and 24 females (22\%). A significant proportion (22\%) was in the $21-30$ and $(22 \%)$ in the $41-50$ year age groups. Sixty males $(70 \%)$ were alcohol addicts. A suicidal note was found at the scene in $17 \%$ of cases. The majority (85\%) of the families had a monthly income of less than $\$ 100 U$ S. Commonest method used by males was hanging (60\%), and by female was plant poisoning $(30 \%)$. The commonest reason for suicide was debt (35\%) and dispute with the spouse/marital disharmony (31\%). Of the 12 adolescent deaths 9 had been due to scolding by parents.

\section{Conclusions}

Majority were young married males belonging to lower socio-economic group. A significant number of teenagers were found to commit suicide following minor disappointments. The method of choice for suicide was hanging among males and plant poisoning among females. Among males, alcohol addiction remains a major contributory factor for committing suicide.

Key words: Suicide methods, Hanging, plant poisoning, debt 


\section{Introduction}

Suicide is considered as a complex event that has biological, psychological and social implications [1]. Historically, suicide has been approached as a personal pathology or a sinful act rather than as a social, structural or genderized phenomenon [2]. The first sociologist who systematically studied suicide as a social occurrence was Durkheim (1951) who claimed that suicide was a social problem rather than an individual illness [3]. Durkheim's exclusive interest was why men killed themselves. Ironically, women have the "highest suicidal behavior" even though more men die as a result of a suicidal act [4]. Since Durkheim, although sociological research on suicide has declined, most research continue to focus on the behaviour of men.

The World Health organization (WHO) estimates that every year, nearly one million people kill themselves [5]. Suicide has become one of the top 20 causes of death in the world over for all ages [5]. For many years now Sri Lanka has been among the countries where suicide and attempted suicide have been frequent frequent.

According to Sri Lanka Sumithrayo organization, an organization set up to help prevent suicide in Sri Lanka, the rate of suicide has reduced from $47 / 100,000$ of the population in 1995 (highest suicidal death rate in the world) to $20 / 100,000$ in 2008 [6].

According to the literature, reasons offered to explain the higher rate of suicide in Sri Lanka include spouse/marital disharmony, financial matters, psychiatric disorders, alcohol dependence, unemployment, broken love affairs, and problems at work $[1,2]$.

\section{Objective}

The objective of this retrospective study was to document epidemiological and socio-economic data on suicides reported to the Teaching hospital, Karapitiya in the year 2011 and to compare with the findings of previous studies done in other parts of the country.

\section{Materials and Methods}

All deaths where a verdict of 'suicide' was issued at the inquest following a post-mortem examination at the Teaching hospital Karapitiya, were retrospectively studied during the oneyear period from $1^{\text {st }}$ of January 2011 to $31^{\text {st }}$ of December 2011. A pre-coded data collection form was developed and ages, sex, marital and occupational status, level of education, living circumstances, and method and reasons for the suicide were studied.

\section{Results}

During the study period, 110 deaths from suicide were found. They were documented and analyzed. The study included 86 men (78\%) and 24 women (22\%).

A significant percentage $(22 \%)$ of those who committed suicide were in the age groups of $21-30$ and another $22 \%$ in the $41-50$ year group. Collectively $59 \%$ was in the $21-50$ year age group, indicating that most of the deaths from suicide occurred among the young and middleaged population (Table 1).

Table 1: Age group of suicide victims

\begin{tabular}{|l|l|l|}
\hline Age group (years) & No & $\%$ \\
\hline $\mathbf{0 0 - 1 0}$ & 00 & $00 \%$ \\
\hline $\mathbf{1 1 - 2 0}$ & 12 & $11 \%$ \\
\hline $\mathbf{2 1 - 3 0}$ & 24 & $22 \%$ \\
\hline $\mathbf{3 1 - 4 0}$ & 17 & $15 \%$ \\
\hline $\mathbf{4 1 - 5 0}$ & 24 & $22 \%$ \\
\hline $\mathbf{5 1 - 6 0}$ & 16 & $14 \%$ \\
\hline $\mathbf{6 1 - 7 0}$ & 11 & $10 \%$ \\
\hline $\mathbf{7 1 - 8 0}$ & 06 & $5 \%$ \\
\hline
\end{tabular}

As shown in Table 2, out of the eighty six males, twenty two (28\%) were single, and out of twenty four females, thirteen (55\%) were single. 
Table 2: Marital status of suicide victims

\begin{tabular}{|l|l|l|l|l|}
\hline & \multicolumn{2}{l}{ Males } & \multicolumn{2}{l}{ Females } \\
\hline Marital status & \multicolumn{1}{l}{ No. } & $\%$ & \multicolumn{1}{l}{ No. } & $\%$ \\
\hline Married & 58 & 67 & 10 & 40 \\
\hline Single & 22 & 28 & 13 & 55 \\
\hline Widowed & 00 & 00 & 00 & 00 \\
\hline Living together & 00 & 00 & 00 & 00 \\
\hline Unknown & 00 & 00 & 00 & 00 \\
\hline Separated & 00 & 00 & 00 & 00 \\
\hline Divorced & 6 & 5 & 1 & 5 \\
\hline Total & 86 & & 24 & \\
\hline
\end{tabular}

Sixty males (70\%) were alcohol addicts. A suicidal note was found at the scene in $17 \%$ of cases.

Occupational status of victims showed that not a single professional had committed suicide in this population (Table 3 ).

Table 3: Occupational status of victims

\begin{tabular}{|l|l|l|}
\hline Occupation & No & $\%$ \\
\hline Unemployed & 39 & $35 \%$ \\
\hline Unskilled & 30 & $27 \%$ \\
\hline Semiskilled & 20 & $18 \%$ \\
\hline Skilled & 18 & $16 \%$ \\
\hline Professional & 00 & $00 \%$ \\
\hline Clerical and related work & 03 & $02 \%$ \\
\hline Managerial and administration & 00 & $00 \%$ \\
\hline
\end{tabular}

Of the study population, approximately $38 \%$ were illiterate or barely literate, without any formal training. The proportion of those who had gone beyond high school was less than 20\%. (Table 4).

Table 4: Level of education

\begin{tabular}{|l|l|l|}
\hline Level of education & No. & $\%$ \\
\hline None & 09 & $08 \%$ \\
\hline Year 01-05 & 33 & $30 \%$ \\
\hline Year 06-11 & 22 & $20 \%$ \\
\hline Year 12-13 & 22 & $20 \%$ \\
\hline Degree or higher & 13 & $12 \%$ \\
\hline Not known & 11 & $10 \%$ \\
\hline
\end{tabular}

The majority (85\%) of the families had a monthly income of less than $\$ 100$ US
Living circumstances showed that the majority, (80 subjects - 73\%), were living with the family at the time of committing suicide (Table 5).

Table 5: Living circumstances of the victim

\begin{tabular}{|l|l|l|}
\hline $\begin{array}{l}\text { Living circumstances on day of } \\
\text { suicide }\end{array}$ & No. & $\%$ \\
\hline With family (including partner) & 80 & $73 \%$ \\
\hline With others (e.g. friends) & 09 & $8.5 \%$ \\
\hline Alone & 10 & $9.5 \%$ \\
\hline Not known & 4 & $3.5 \%$ \\
\hline Lodging/hostel & 4 & $3.5 \%$ \\
\hline Other institution & 3 & $2 \%$ \\
\hline
\end{tabular}

Eighty percent committed suicide at their dwelling place. Sixteen percent of deaths due to suicide were reported during the month of April. About $42 \%$ had been in contact with medical personnel in the month before their death.

Analysis of the method of suicide (Table 6) showed that hanging was the commonest method ( $n=56 ; 51 \%)$ Agrochemical substances accounted for 37 (33\%) of deaths. Paraquat was the commonest pesticide used (11\%). Other common causes of death includes plant poisoning (6\%), "Prinso poisoning"( a detergent comprising of potassium permanganate and oxalic acid) (4\%) and corrosive poisoning (3\%).

Commonest method used was hanging in males $(60 \%)$, and plant poisoning in females (30\%).

Table 6: Method of suicide

\begin{tabular}{|l|l|l|l|l|}
\hline & \multicolumn{2}{|l|}{ Male } & \multicolumn{2}{l|}{ Female } \\
\hline & No & $\%$ & & \\
\hline Hanging & 51 & $60 \%$ & 05 & $21 \%$ \\
\hline Agrochemical & 32 & $37 \%$ & 05 & $21 \%$ \\
\hline Corrosives & 03 & $3 \%$ & 00 & $0 \%$ \\
\hline Plant poisoning & 00 & $0 \%$ & 07 & $30 \%$ \\
\hline Prinso & 00 & $0 \%$ & 05 & $21 \%$ \\
\hline $\begin{array}{l}\text { Medicinal } \\
\text { drugs }\end{array}$ & 00 & $0 \%$ & 02 & $7 \%$ \\
\hline Total & 86 & & 24 & \\
\hline
\end{tabular}

According to the evidence given at the inquest, the commonest reason for suicide was debts (35\%) followed by dispute with the spouse 
(31\%) (Table 7). Of the 12 adolescent deaths 9 had been due to scolding by parents. Past history of psychiatric illness was present in $10 \%$ and previous attempts of suicide was reported in $7 \%$.

Table 7: Reason given at the inquest for committing suicide

\begin{tabular}{|l|l|l|}
\hline Reason given & No & \% \\
\hline Financial matters & 39 & $35 \%$ \\
\hline Dispute with spouse & 33 & $31 \%$ \\
\hline Dispute with parents & 16 & $15 \%$ \\
\hline Disputes in love affairs & 09 & $8 \%$ \\
\hline Problems at work & 4 & $3 \%$ \\
\hline Dispute with children & 4 & $3 \%$ \\
\hline Alcohol dependence & 3 & $3 \%$ \\
\hline Psychiatric disorders & 2 & $\mathbf{2} \%$ \\
\hline
\end{tabular}

\section{Discussion}

Suicidal behavior and, in particular, the preferred suicide method varies between countries [7]. Some patterns are well known, such as the high percentage of firearm suicides in the United States of America [8]. In addition, the role of pesticide suicide in Asian countries became apparent in the 1990s [7].

While numerous factors contribute to the choice of a suicide method, societal patterns of suicide can be understood from basic concepts such as the social acceptability of the method (i.e. culture and tradition) and its availability (i.e. opportunity). International or intercultural comparisons of suicide methods help increase the understanding of the interplay between these two factors and provide a basis for preventive strategies.

In 2008, 3260 men (79\%) and 860 women (21\%), (total 4120) committed suicide in Sri Lanka and in 2009, 1609 men (77\%) and 465 women (23\%), (total 2074) committed suicide [6]. The male-to-female ratio was around 5:1. In the present study the male to female ratio was around 3.5: 1 (male 78\% and female 22\%).

In our study the victims of suicide were mostly young, married men who had interpersonal problems with their families which they could not handle. Similar observations were made in previous studies done within Colombo city limits in 2006[1] and in the Department of Forensic Medicine, Galle in 2009[9]. However, the male-to-female ratio shows that a significant number of women too had committed suicide.

A significant number of deaths were reported (11\%) from the age group of $11-20$ years. Similar findings were observed in other studies as well $[1,9]$. Measures need to be taken to address these teenage suicidal trends.

Most of the victims were of a low socioeconomic status; $35 \%$ were unemployed and $45 \%$ had been working as semiskilled or unskilled workers. Not a single professional committed suicide in this study. This indicates that the pressures were commoner among the lower socioeconomic class. Highest number of suicides was reported during the month of April (16\%). This also could be due to the increased expenditures during the festival season causing more stress. Similar findings were observed during the 2009 study at the Department of Forensic Medicine, Galle [9].

Of the study population, approximately $38 \%$ were illiterate or barely literate, without any formal training. Two fifths had completed primary school $(20 \%)$ or high school education (20\%). The proportion of those who had studied beyond high school was less than $20 \%$. Similar findings were observed during the 2009 study at the Department of Forensic Medicine, Galle [9].

In previous studies done at Colombo city limits in 2006 [1] and in the Department of Forensic Medicine, Galle in 2009[9], pesticide ingestion was the commonest method of suicide among both the males and females (42\%). But in this study, commonest method of suicide used by males was found to be hanging $(60 \%)$ and the commonest method used by females was found to be plant poisoning (30\%).

From the time the first case of pesticide poisoning was reported in Sri Lanka in 1962, pesticide poisoning reached epidemic proportions in the 1990s[1]. Acute pesticide 
poisoning is a major health problem and in several agricultural districts it is the principal cause of death in hospitals [10]. Reduction in the number of suicidal deaths due to pesticide ingestion is a very significant finding in this study. In all the studies conducted in this regard in the past in Sri Lanka, the commonest method of suicide was found to be the pesticide ingestion. This is the first time; a change has been reported in this country. The reason for this change needed to be studied further. The possible reasons are improved management of pesticide poisoning patients in the hospitals, and the measures taken by the authorities to ban some of the very toxic pesticides in Sri Lanka.

Not a single case of self immolation had been reported during this period. Newer methods like "Prinso" poisoning was found to be popular (20\%) among the female victims.

Debt and marital disharmony was the main reason for committing suicide (66\%). Psychiatric illnesses were responsible for only $2 \%$ of suicides. Studies done in the past have shown that only $20 \%$ had a psychiatric illness and the rest were considered to have impulsive personalities'[11]. The finding in our study also suggests that the majority of suicide attempts were due to sudden impulse.

Sixty males (70\%) were alcohol consumers and this remains a major contributory factor for committing suicide.

\section{Conclusions}

Majority were young married males belonging to lower socio-economic group. A significant number of teenagers were found to commit suicide following minor disappointments. Method of choice was hanging among males and plant poisoning among females. A significant reduction in suicides by pesticide poisoning can be seen. It should be noted that a new washing powder called 'Prinso' is being used as a method of suicide popularly among females. It was evident that both social and personal causes had contributed. Majority had been first timers. Among males, alcohol addiction remains a major contributory factor for committing suicide.

\section{References}

1. Fernando R, Hewagama M, Priyangika W, Range SS, Karunaratne S. Study of suicides reported to the Coroner in Colombo, Sri Lanka. Med Sci Law 2010;50(1):25-28.

2. Isaacs S, Keogh S, Menard C, Hockin J. Suicide in the Northwest Territories: a descriptive review. Chronic Dis Can 1998;19(4):152-6.

3. A. Sev'er \& R. Erkan. The dark faces of poverty, patriarchal oppression, and social change: Female suicides in Batman, Turkey. Women and International Development Journal. 2004. 282: 1-24.

4. Garro LC. Suicides by status Indians in Manitoba. Arctic Med Res 1988;47 (Suppl 1):590-2.

5. Lesage $A D$, Boyer $R$, Grunberg $F$, Vanier $C$, Morissette $R$, Ménard-Buteau $C$, et al. Suicide and mental disorders: a casecontrol study of young men. Am J Psychiatry 1994;151:1063-8.

6. Sri Lanka Sumithrayo:Statistics and data: availableat http://srilankasumithrayo.org/statistics-adata; viewed on 21/01/2012.

7. Eddleston $M$, Sheriff $M H$, Hawton $K$. Deliberate self harm in Sri Lanka: an overlooked tragedy in the developing world. British Medical Journal 1998; 317: 133-5.

8. Chan KP, Yip PS, Au J, Lee DT. Charcoalburning suicide in post-transition Hong Kong. British Journal of Psychiatry 2005; 186: 67-73.

9. Vidanapathirana M,Rathnaweera R.H.A.I. A study on deaths due to suicides, based on cases reported to Teaching Hospital Karapitiya from 2007 to 2009. The College of Forensic pathologists of Sri Lanka annual academic sessions 2009. 
10. Hettiarachchi J, Kodituwakku GCS, Chandras iri N. Suicide in Southern Sri Lanka. Med Sci Law 1988;28:248-51.

11. Senanayake $\mathrm{N}$, Peiris H. Mortality due to poisoning in a developing agricultural country: trends over 20 years. Hum ExpToxicol 1995;14:808-11. 